\title{
Paediatric neck ultrasonography: a pictorial essay
}

\author{
Maria Grazia Caprio ${ }^{1}$ Marco Di Serafino ${ }^{2}\left[\right.$. Giuseppe Pontillo $^{1} \cdot$ Norberto Vezzali $^{3} \cdot$ Eugenio Rossi $^{4}$. \\ Francesco Esposito ${ }^{4} \cdot$ Massimo Zeccolini $^{4}$. Gianfranco Vallone ${ }^{1}$
}

Received: 15 April 2018 / Accepted: 1 August 2018 / Published online: 5 September 2018

(c) Società Italiana di Ultrasonologia in Medicina e Biologia (SIUMB) 2018

\begin{abstract}
The neck structures are located very superficially and are therefore easy to explore by ultrasound examination. Ultrasonography is crucial for the detection of neck pathologies in children. High-frequency probes $(10-15 \mathrm{MHz})$ are used for the ultrasound examination on the patient lying in supine decubitus and with their neck stretched out. The outcome of the exam depends mainly on the child's cooperation-hence the need for warm sonographic gel and a comfortable cushion to place under the patient's shoulders. The complete scan of the neck includes the evaluation of the thyroid and salivary glands and the vascular structures as well as the lymph node analysis. In children and adolescents, the thymus is often visualised in the supraclavicular and jugular scans. It appears as a structure, usually hypoechoic, with thin hyperechoic straps, though echogenicity increases with age. In this pictorial essay, the main pathological conditions of the neck in paediatric age will be examined, such as thyroid dysgenesis, thyroiditis, thyroid nodules, lymphadenopathies, cystic lesions, haemangiomas and vascular malformation, cervical thymus, fibromatosis colli and pilomatrixoma.
\end{abstract}

Keywords Ultrasound examination $\cdot$ Neck structures $\cdot$ Paediatric age $\cdot$ High-frequency probes

\section{Sommario}

Le strutture del collo sono localizzate molto superficialmente, quindi facili da esplorare con l'esame ecografico. L'ecografia è fondamentale per la rilevazione delle patologie del collo nei bambini. Per l'esame ecografico vengono utilizzate sonde ad alta frequenza (10-15 MHz) con il paziente in decubito supino e con il collo iperesteso. L'esito dell'esame dipende principalmente dalla cooperazione del bambino - da qui la necessità di un gel ecografico caldo e un comodo cuscino da posizionare sotto le spalle del paziente. La scansione completa del collo comprende la valutazione della tiroide e delle ghiandole salivari, delle strutture vascolari e l'analisi dei linfonodi. Nei bambini e negli adolescenti, il timo è spesso visualizzato nelle scansioni sovraclaveari e giugulari. Appare come una struttura solitamente ipoecogena con sottili strie iperecogene, sebbene l'ecogenicità aumenti con l'età. In questo saggio pittorico verranno esaminate le principali condizioni patologiche del collo in età pediatrica, quali disgenesia tiroidea, tiroidite, noduli tiroidei, linfoadenopatie, lesioni cistiche, emangiomi e malformazioni vascolari, timo cervicale, fibromatosis colli e pilomatrixoma.

\section{Introduction}

Marco Di Serafino

marcodiserafino@hotmail.it

1 Paediatric Radiology Department, "Federico II" University Hospital, Naples, Italy

2 Radiology Department, "Antonio Cardarelli" Hospital, Naples, Italy

3 Radiology Department, Regional Hospital of Bolzano, Bolzano, Italy

4 Radiology Department, "Santobono-Pausilipon” Children Hospital, Naples, Italy
The structures of the neck are located quite superficially and are therefore easily inspectable on a scan. Ultrasonography is crucial for the detection of neck pathologies in children. The main indicators for ultrasound examination are congenital hypothyroidism, thyroidal/nodular pathologies and differential diagnosis of neck tumefactions, as well as perviety evaluation of both the jugular and subclavian veins before central venous catheter insertion [1]. 


\section{Ultrasonographic aspects and techniques}

Ultrasound examination of children presents some complications, mainly related to the little patients' resistance to maintaining the right position. The outcome of the exam depends mainly on the child's cooperation-hence the need for warm sonographic gel and a comfortable cushion to place under the patient's shoulders. Ultrasound examinations are very sensitive to motion, and an active or crying child can prolong the examination process. To ensure a smooth experience, it often helps to explain the procedure to the child prior to the exam. Using books, small toys, music or games can help distract the child and pass the time more quickly.

During the scan, linear high-frequency $(10-15 \mathrm{MHz})$ probes are employed on the patient lying in supine decubitus and with their neck stretched out. The complete scan of the neck includes the evaluation of the thyroid and salivary glands, the thymus and the vascular structures and the lymph node analysis.

The thyroid is an endocrine gland located in the anteromedian region of the neck. The normal thyroid gland comprises two lobes connected by an isthmus. Thyroid size, shape and volume vary with age and sex. Normal thyroid lobe dimensions are: $18-20 \mathrm{~mm}$ longitudinal and $8-9 \mathrm{~mm}$ antero-posterior (AP) diameter in a newborn and $25 \mathrm{~mm}$ longitudinal and 12-15 mm AP diameter at 1 year of age [2].

During the exam, it is essential to follow a systematic approach to not lose any information. To this end, the American College of Radiology recommends proceeding as follows: [3]

1. perform cross-sectional scans of the entire gland, comparing the two lobes and measuring the anterior-posterior and transverse diameters;

2. make longitudinal scans, measuring the longitudinal diameter;

3. identify any focal lesions, measuring the largest one, where present;
4. assess the presence of enlarged lymph nodes in the neck using transversal and longitudinal scans on the neck.

The glandular structure normally appears to contain more echogenic echoes than the pre-thyroid muscle structure. It is homogeneous (Fig. 1).

On the colour Doppler examination, arterial vessels, peripheral venous vessels and sporadic intraparenchymal spots are present.

The glandular volume can be obtained through the ellipsoidal formula (anteroposterior diameter $\times$ transversal diameter $\times$ longitudinal diameter $\times 0.52 \times 2)($ Table 1$)$.

The salivary glands appear very clearly on a scan; this is especially true for the parotid and submandibular glands.

The parotid gland is located in the retromandibular fossa, anterior to the ear and sternocleidomastoid muscle. Parts of the superficial lobe cover the ramus of the mandible and the posterior part of the masseter muscle. The submandibular gland lies in the posterior part of the submandibular triangle. The anterior and posterior bellies of the digastric muscle and the body of the mandible create the sides of the submandibular triangle. The normal echogenicity of all major salivary glands is generally homogeneous and varies from very bright and markedly hyperechoic to only slightly hyperechoic in comparison

Table 1 Median values (P50) and 97th percentile (P97) of thyroid volume $\left(\mathrm{cm}^{3}\right)$ in children according to age and sex

\begin{tabular}{llllll}
\hline Years old & \multicolumn{2}{l}{ Boys } & & \multicolumn{2}{l}{ Girls } \\
\cline { 2 - 3 } & P50 & P97 & & PS0 & P97 \\
\hline 6 & 2.3 & 3.8 & 2.1 & 3.6 \\
7 & 2.4 & 4.0 & 2.4 & 4.2 \\
8 & 2.6 & 4.3 & 2.8 & 4.9 \\
9 & 2.9 & 4.8 & 3.1 & 5.7 \\
10 & 3.2 & 5.5 & 3.6 & 6.5 \\
11 & 3.6 & 6.4 & 4.0 & 7.4 \\
12 & 4.0 & 7.4 & 4.5 & 8.3 \\
\hline
\end{tabular}

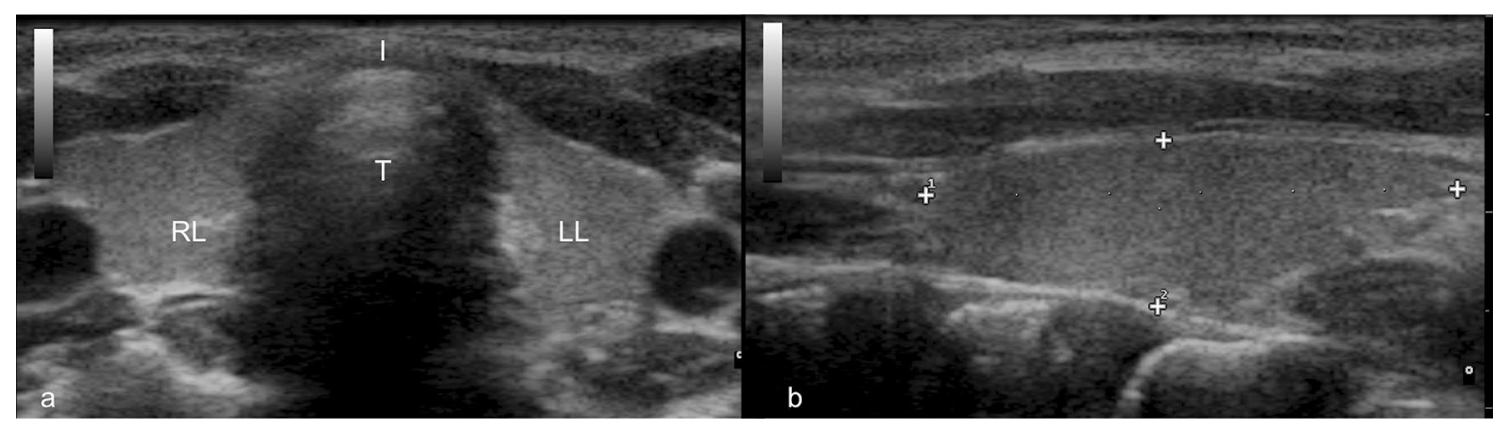

Fig. 1 Normal thyroid gland. a Axial and $\mathbf{b}$ longitudinal (length, ++ ) section. $R L$ right thyroid lobe gland, $L L$ left thyroid lobe gland, $I$ isthmus, $T$ trachea 
to adjacent muscles. The echogenicity depends on the amount of intraglandular fatty tissue [4, 5] (Fig. 2).

The parotid is the most commonly affected gland in paediatric age.

The neck carries vital arteries that transmit blood to the brain, head and face. It also contains the veins that drain deoxygenated blood from the brain, head and face and return it to the right side of the heart. Some of these structures travel together in a fascial sheath (connective tissue) called the carotid sheath, which carries the common and internal carotid arteries, the internal jugular vein, the vagus nerve (cranial nerve $\mathrm{X}$ ), some lymph nodes, the carotid periarterial plexuses and the carotid sinus nerve.

In the neck, there are more than 300 lymph nodes, which used to be classified into groups according to their location, according to the TNM classification AJCC and UICC, 2002:

Level I: $\quad$ submental and submandibular nodes;

Level II: upper jugular nodes-between the posterior belly of the digastric muscles superiorly and the hyoid bone inferiorly;

Level III: middle jugular nodes—-between the hyoid bone and the cricoid cartilage;
Level IV: lower jugular nodes—between the cricoid cartilage and the clavicle;

Level V: posterior cervical or spinal accessory nodesposterior to the sternocleidomastoid muscle;

Level VI: visceral space lymph nodes - the midline group of cervical nodes from the hyoid to the sternal manubrium, includes the prelaryngeal, pretracheal, and paratracheal subgroups;

Level VII: Superior mediastinal nodes-between the carotid arteries from the top of the manubrium superiorly to the innominate vein inferiorly.

\section{Thyroidal diseases}

\section{Thyroid dysgenesis}

It includes a series of conditions (aplasia, hypoplasia, hemiplasia, and ectopia) which together represent the main cause of congenital hyperthyroidism (about $85 \%$ of all cases). The most common anomalies include ectopic thyroid, in which the gland can dislocate anywhere along the embryonal thyroid, usually near the upper thyroid region at the base of the tongue [6] (Fig. 3).

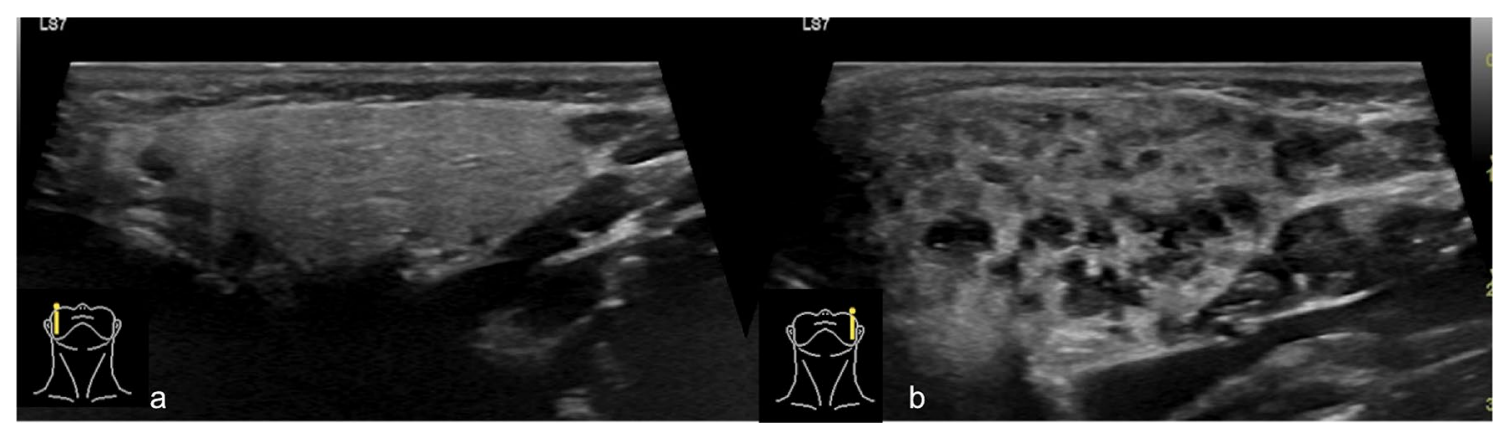

Fig. 2 Salivary gland. Normal parotid gland. Salivary glands appear very clearly on a scan: this is especially true for the parotid and submandibular gland. In normal conditions, salivary glands are homoge- neously hyperechoic (a). The parotid is the most commonly affected gland in paediatric pathologies (b)
Fig. 3 Ectopic thyroid (white arrowheads) situated at the base of the tongue. B-mode (a) and colour Doppler module (b)
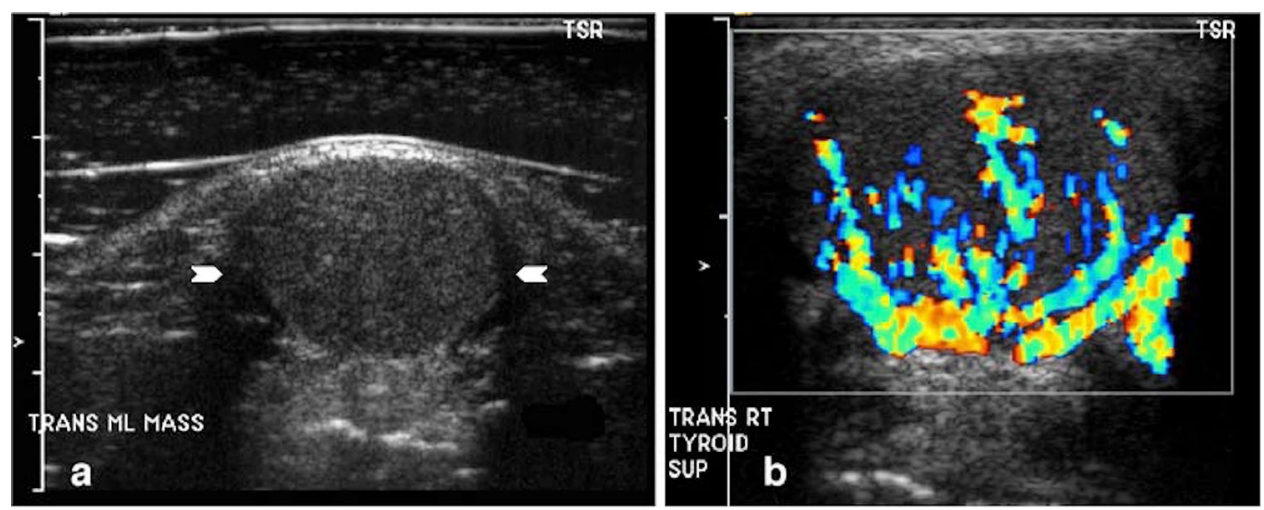
In $10 \%$ of cases, hypothyroidism is caused by molecular defects that alter the process of uptake, organification or secretion of thyroid hormones. Another situation to be considered as a differential diagnosis is neonatal transient hypothyroidism, which may be related to a deficiency or excess of iodine during pregnancy, neonatal suffering or immaturity of the hypothalamic-hypophyseal axis.

In aplasia, there is a total lack of the thyroid. The thyroid lodge can be totally uninhabited or occupied by a variable amount of adipose tissue, which will appear hyperechoic.

In hypoplasia, the gland appears normal to ultrasound examination; under scintigraphy, however, there is a reduction in uptake. In hemiplasia, there is a lack of one of the two thyroid lobes. This diagnosis is usually incidental. The levels of thyroid hormones are in most cases normal but can be reduced in those situations, such as puberty, where greater amounts are required.

Thyroid ectopia consists of a deficiency in the migration of the gland during its embryogenesis. In these cases, the thyroid is usually sub-lingual. When this pathology is suspected, it is therefore necessary to extend the ultrasound examination to the base of the tongue, looking for the ectopic thyroid tissue along the whole course of the thyroglossal duct. It should be remembered that in $75 \%$ of cases, the ectopic tissue is the only functioning one [7].

\section{Thyroiditis}

Thyroiditis is an inflammatory process affecting the thyroid. Its nature, as well as its clinical course, can be very heterogeneous. The gland usually appears hypoechoic due to inflammatory infiltration and the evolution of the process can lead to atrophy and fibrosis. Let us examine below the most frequent forms of thyroiditis in the child: the most common thyroiditis in children is Hashimoto's disease-on scan the gland can appear enlarged, presenting a roughly diffused and heterogeneous structure and multiple hypoechoic micronodules. Sometimes intraglandular fibrous septa are found (Fig. 4). The colour Doppler signal can be increased in the acute phase and normal or reduced in the chronic phase.

\section{Thyroid nodules}

Thyroid nodules are quite rare in puberty $(<1.5 \%$ of thyroid diseases). In the vast majority of cases - about $85 \%$ lesions are benign (adenomas, cysts) (Fig. 5). The ultrasound examination is the first-level survey, possibly followed by FNA (fine-needle aspiration), which has 90-95\% diagnostic accuracy in paediatric patients. As this procedure requires sedation, the risks must be carefully assessed in the context of a cost-benefit balance.

The majority of benign thyroid nodules are the result of hyperplasia and become cystic formations. Ultrasound parameters of benignity are:

- hyper- or iso-echoes, possibly with a contextual cystic area;

- regular margins;

- hypoechoic halo, due to the presence of a capsule or for the compression of the adjacent parenchyma;

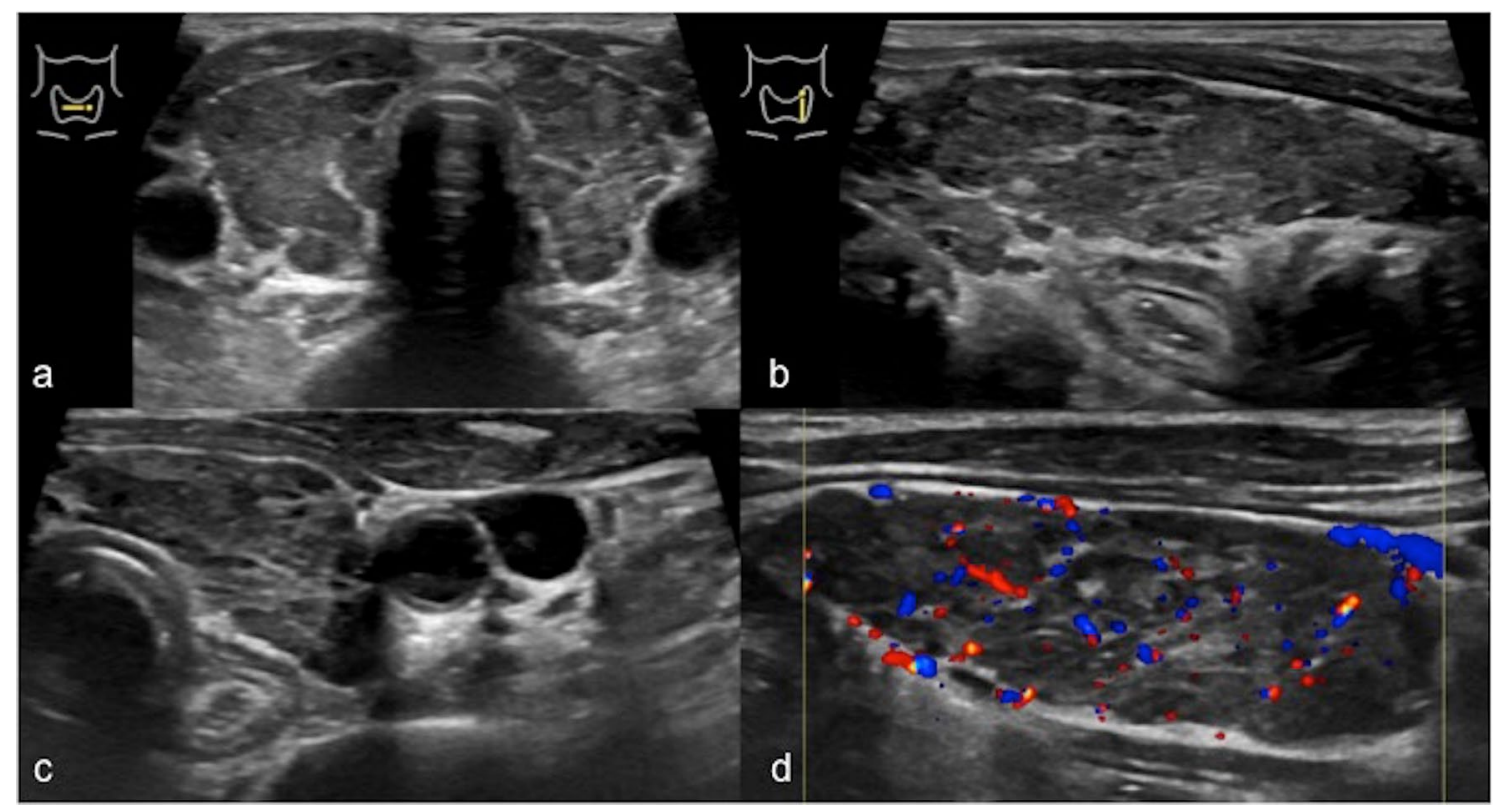

Fig. 4 Thyroiditis. Axial (a, c) and longitudinal $(\mathbf{b}, \mathbf{d})$ scans of thyroid show a heterogeneously enlarged gland with multiple hypoechoic micronodules. At times intraglandular septic fibroids are found. Colour Doppler shows normal vascular signals in chronic phase (d) 


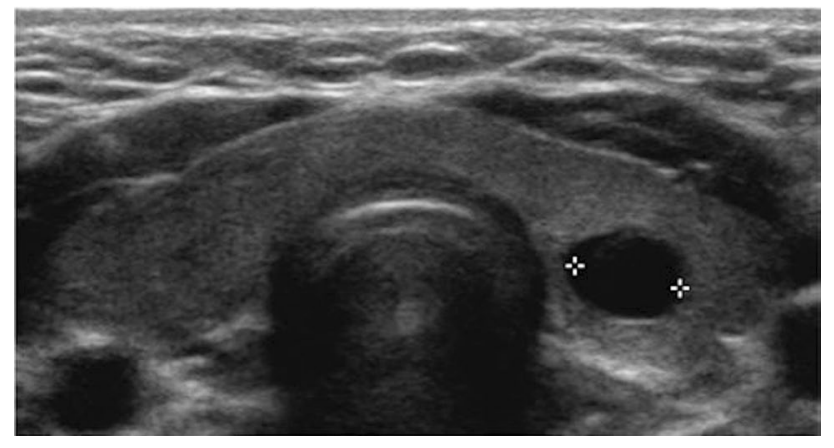

Fig. 5 Thyroid nodules. Axial scan of thyroid shows a cystic nodule $(++)$ on the left lobe

- cystic appearance with no internal solid tokens;

- presence of the "ring down" sign, caused by the presence of the colloid;

- macrocalcifications (>2 mm), 'eggshell' peripherals or 'iceberg' intranodular devices.

At colour Doppler, the vascular pattern is peripheral, with thin intranodular vessels, and at regular disposal (ring sign), while the malignant one is more frequently chaotic and intranodular, with numerous coarse and irregularly arranged vessels.

Thyroid nodules are malignant only in $15 \%$ of cases and are rare under 15 years. They have an incidence of 0.5 cases per million and are often related to a previous irradiation of the neck. In $80 \%$ of cases this is papillary carcinoma (80\%), followed by follicular (17\%), then medullary $(2-3 \%)$.

In $17 \%$ of cases, there may be a presence of intra-thyroid thymus areas, which may be erroneously reported as thyroid nodules. These areas of ectopia are due to an incorrect migration of the thymus during its organogenesis and appear on the ultrasound examination as hypoechoic areas with fine hypoechogenic point-like echoes, poorly delimited, in the context of the thyroid [8].

\section{Lymphadenopathies}

Normal cervical lymph nodes are detectable with ultrasound in healthy people. At least five or six normal cervical nodes are identified routinely by sonography. The number of cervical lymph nodes that can be detected by ultrasound decreases with advancing age [9].

Among the different regions of the neck, normal cervical lymph nodes are commonly found in submandibular (19-23\%), parotid (15-16\%) and upper cervical (18-19\%) regions, as well as the posterior triangle (35-37\%) [10].

Normal lymph nodes appear oval-shaped, with a moderately echoic structure, hyperechoic at the hilum region, where vessels are also visible under colour Doppler.

Lymph nodes bigger than $1 \mathrm{~cm}$ are considered pathological — though jugulodigastric lymph nodes at the jaw angles are considered normal up to $2 \mathrm{~cm}$ [11].

Reactive lymph nodes appear to be larger on Doppler but maintain an oval morphology and hyperechoic hilum along with a preserved vascular architecture (Fig. 6). They are very often found in patients affected by upper-respiratory tract infections or head and neck diseases. Inflamed lymph can turn necrotic and form abscesses [12] (Fig. 7).

Malignant lymph nodes (lymphoma, leukaemia, metastasis) tend to be roundish and show a hypoechoic echo structure, loss of the hyperechoic hilum and prevalently cortical vascularisation (Fig. 8). Supraclavicular localisation is particularly suggestive of malignity.

\section{Cystic lesions}

\section{Thyroglossal duct cysts}

Thyroglossal duct cysts are the most frequent malformative pathology of the neck in children. They represent $72 \%$ of cervical dysontogenic neoformations. They mainly affect females and occur in half of cases within the first 5 years of life [13].

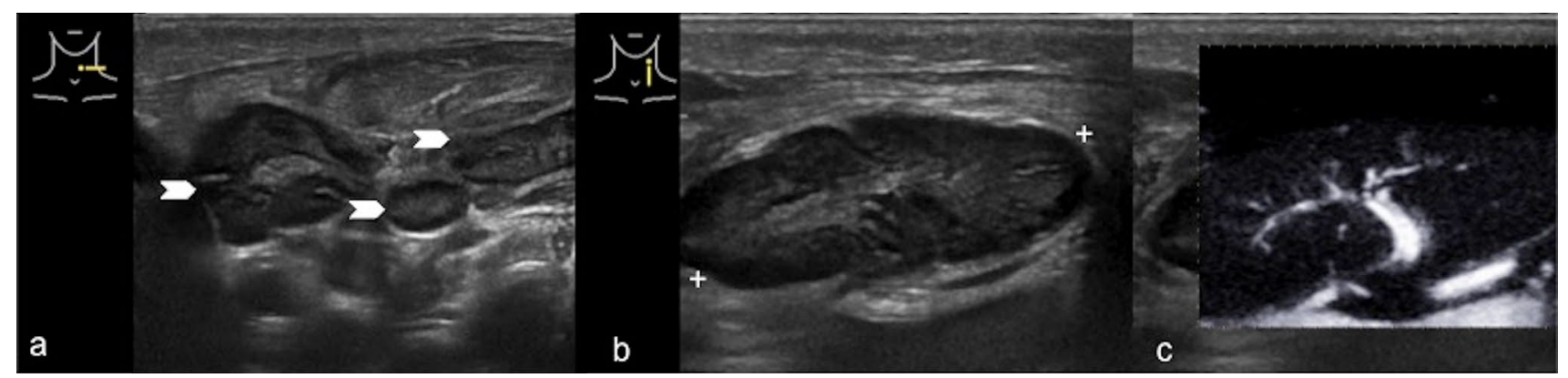

Fig. 6 Reactive lymph node. a Split image, sagittal lateral left neck-grouped spherical enlarged lymph nodes (arrowheads). b Extended field of view, similar region: a large node (++). c A preserved vascular hilum architecture of colour Doppler 
The pathogenesis seems to be related to a reabsorption defect, at any level of the course, of the thyroglossal duct. The residual cellular elements assume serum-mucosal secretory capacities, such as to favour the formation of a cyst. The cyst is intimately connected with the hyoid bone and the blind foramen through a duct. The secretion usually drains in the region of the blind foramen. If this drainage point is obstructed, secretions will accumulate, increasing the volume of the cyst. The fistula, a relatively infrequent complication, is one consequence of the inflammation with a spontaneous external opening of the cyst.

Usually thyroglossal duct cysts are asymptomatic. They are located on the midline of the neck and can be located anywhere on the course of the thyroglossal duct, from the base of the tongue to the suprasternal area.
The ultrasound of the neck allows the detection of the solid or liquid content of the cyst; it is also useful for identifying the position and morphology of the thyroid.

This type of cyst is typically displayed as a finely delimited anechoic or hypoechoic formation located deep within or incorporated into the thyroid-hyoidal muscle. Mobility is observed during swallowing (Fig. 9).

In the presence of a non-fully cystic tumefaction or when the thyroid gland is not detected clinically or with ultrasound, a scintigraphy may be useful. In cases of difficult diagnosis, CT and MRI are used, providing the greatest opportunity to study the wall, content and anatomical relationships $[14,15]$. Complications of the cyst include infection, haemorrhage and rupture, as well as cutaneous fistula [16] (Fig. 10).
Fig. 7 Suppurated lymph node. a Large suppurated lymph node $(++)$. b Fistula tract (arrowhead) in necrotising lymph node abscess (*)
Fig. 8 Malignant lymph node. Malignant lymph nodes (lymphoma, leukemia, and metastasis) tend to be roundish and show hypoechoic echostructure, loss of the hyperechoic hilum and prevalently cortical vascularisation
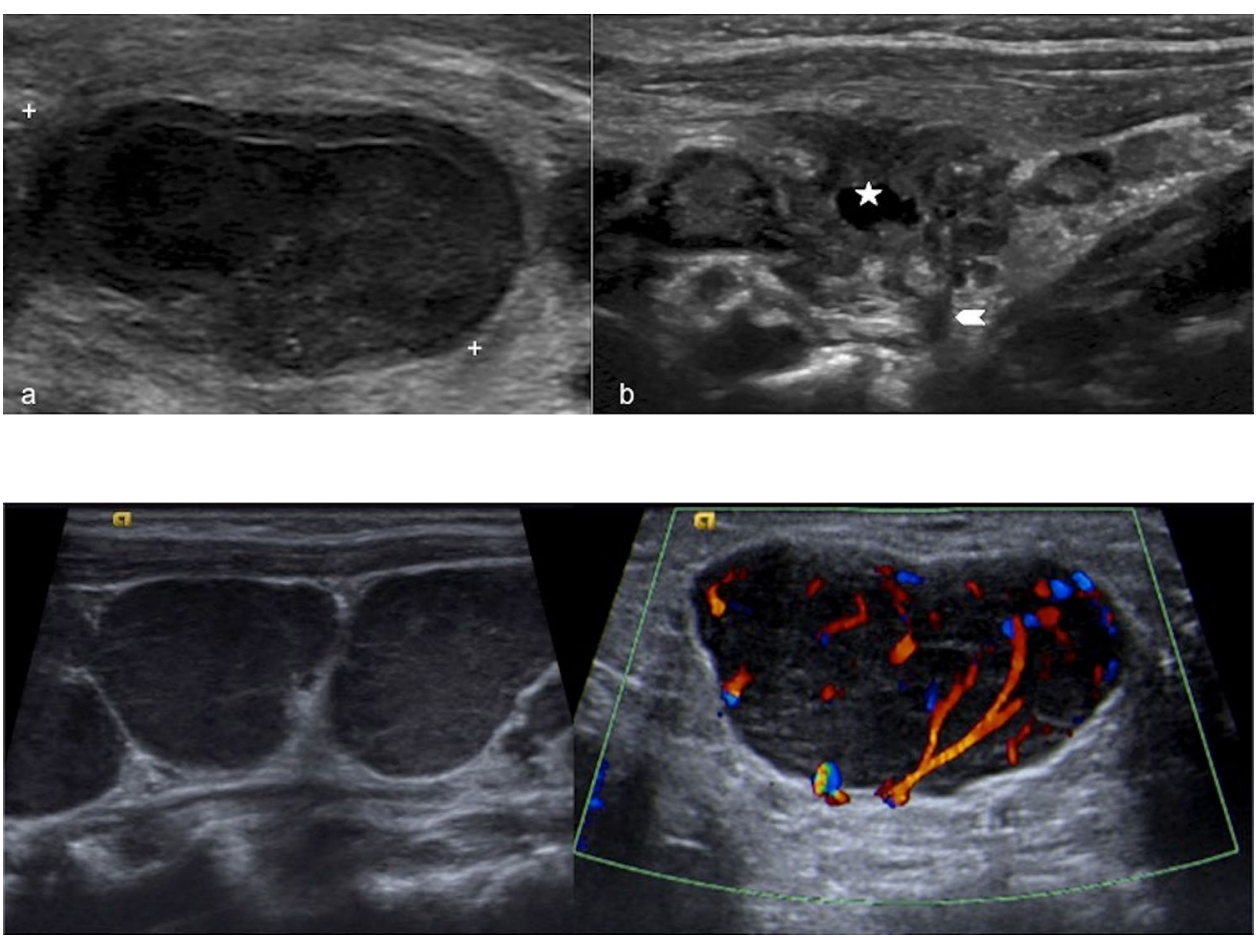

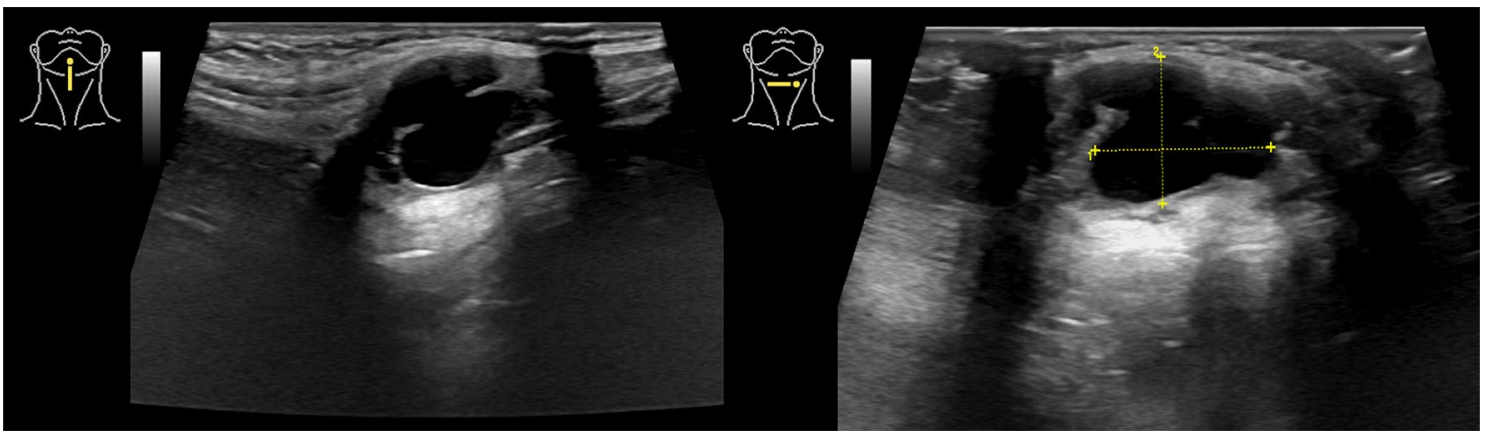

Fig. 9 Thyroglossal duct cyst. A finely delimited anechoic (++) mass deeply located or incorporated into the thyroid-hyoideal muscle 
Fig. 10 Thyroglossal duct cyst complication. a B-mode and b colour Doppler module of sovra-infected thyroglossal duct cyst complication. c, d Cutaneous fistula of complicated thyroglossal duct cyst

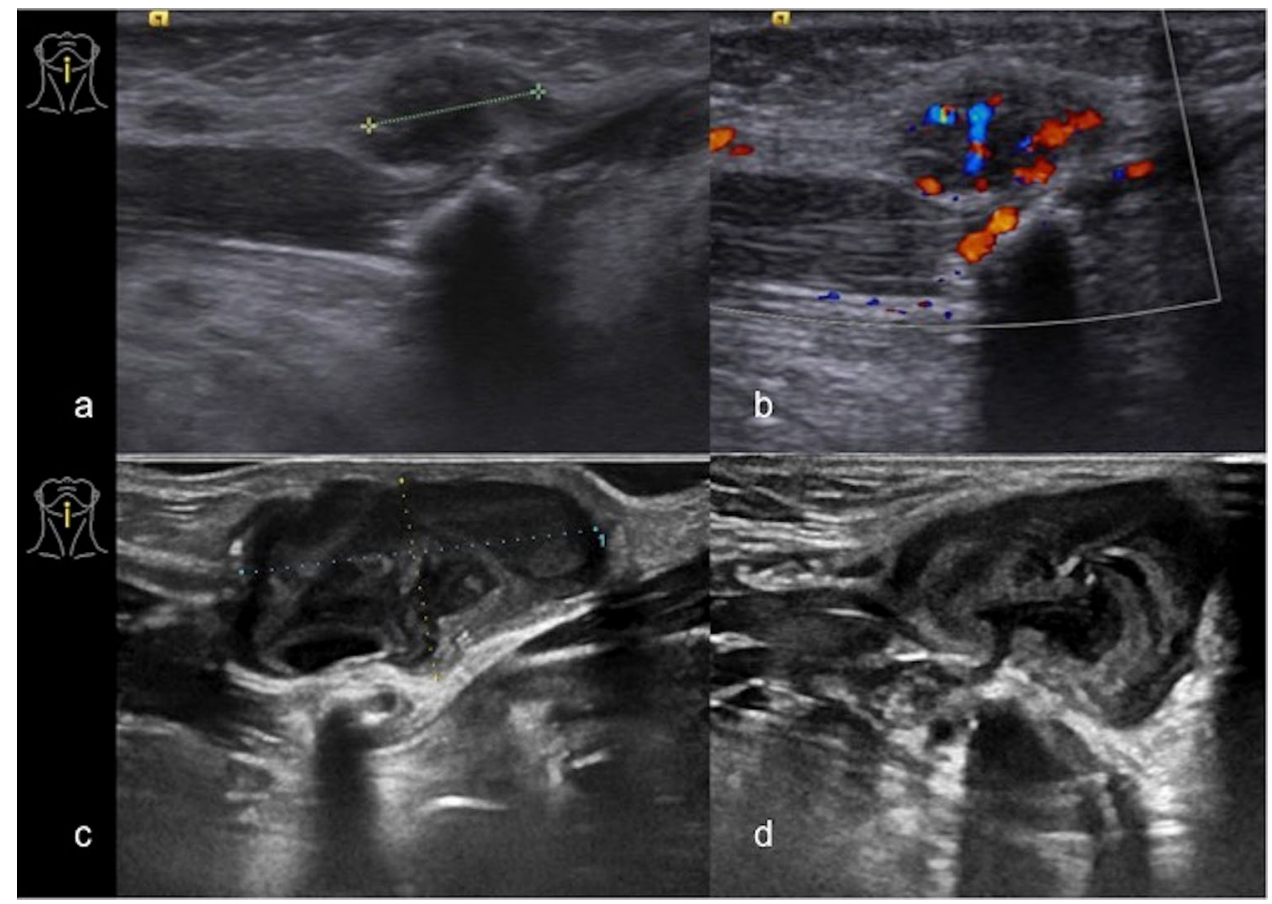

\section{Branchial cysts}

Abnormalities of development of the branchial apparatus can lead to numerous malformations, such as sinuses, fistulas or cysts. The anomalies affect the second branchial sulcus about $75 \%$ of the time and the first $20 \%$; the remaining cases affect the third and fourth [17].

Although of congenital dysplastic origin, these cysts are never identified at birth, only in adolescence or puberty.

They can have a median or lateral seat. Median cysts are very often subhyoidal and originate from the thyroglossal duct. The lateral cysts, usually in close association with the upper third of the sternocleidomastoid muscle, are almost always subhyoidal, derived from the cervical sinus or from the second branchial pocket and exceptionally from the third.

Clinically they present as roundish tumefactions with smooth walls, frequently fluctuating, sometimes transboundable, without reducibility, without increasing with effort or cough (unlike haemo- or lymphangiomas) and with rhythmic expansibility (unlike aneurysms).

Sonographically, they appear as cystic formations with clear margins, thin walls and generally corpusculated content (Fig. 11). These cysts are at high risk of infection and rupture leading to fistula.

\section{Dermoid cysts}

A dermoid cyst is a benign lesion (cystic teratoma) containing differentiated tissue of skin and annexed tissues (sudoriferous glands, hair, and sebaceous glands). Neck dermoid cysts are usually located along the medial line in the subcutis. The shape is ovular or roundish, the margins are defined and the echostructure is variable-homogeneous or heterogeneous depending on the cyst content (Fig. 12).

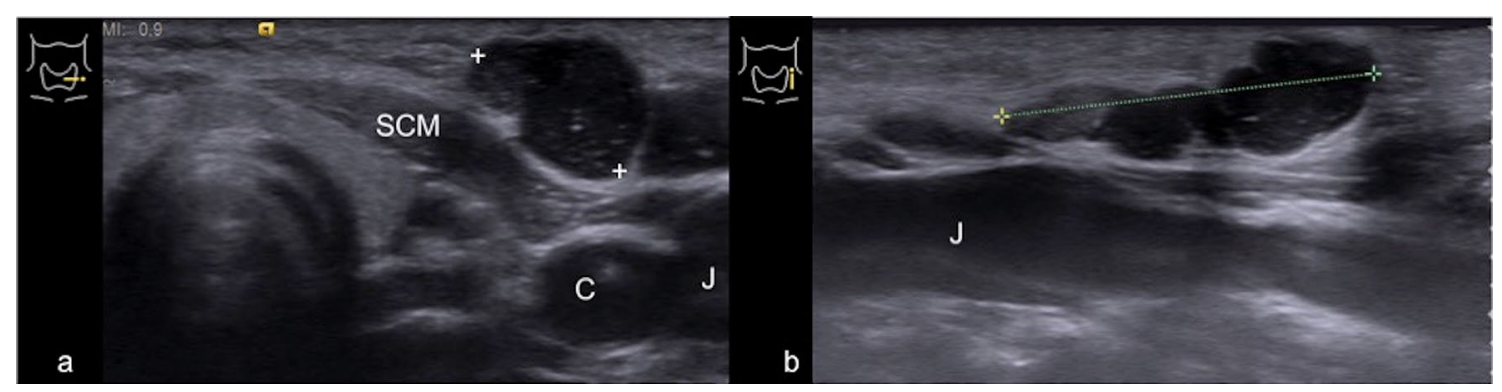

Fig. 11 Branchial cyst. a Axial and b sagittal view of cystic formation with clear margins, thin walls and corpusculated content (++) anteromedial to sternocleidomastoid muscle (SCM) and anterolateral to the vascular carotid (C) jugular (J) axe 


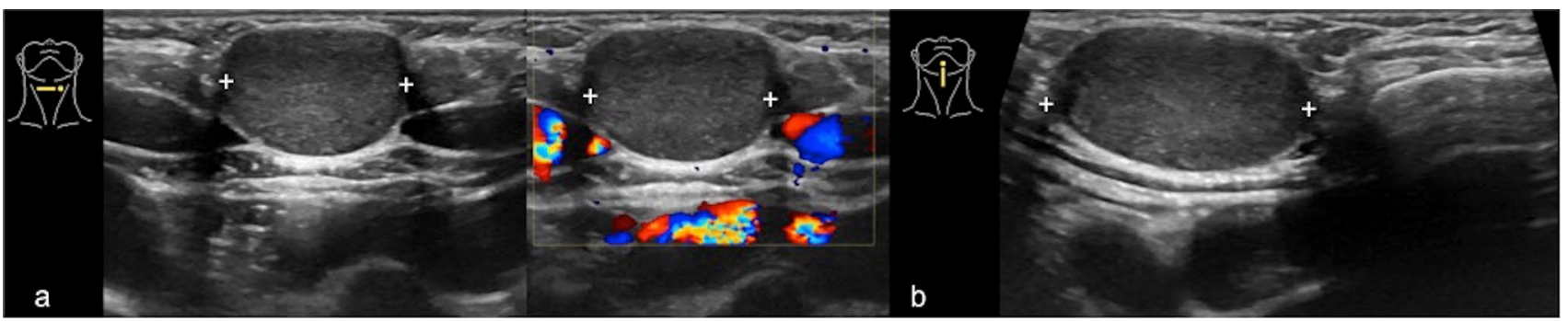

Fig. 12 Dermoid cyst. a Axial and $\mathbf{b}$ longitudinal view of a uvular mass with well-defined margins and homogeneous echostructure (++) located along the medial line in the subcutis

When dermoid cysts are located between the thyroid and the hyoid bone, differential diagnosis with thyroglossal cyst can be difficult.

Histological examination is necessary to diagnose dermoid cysts. They are distinguished from the epidermoid cysts by the presence of cutaneous appendages, such as hair follicles or sebaceous glands, in the context of the cystic wall. Radiologically, dermoid cysts appear as unilocular masses, with a thin wall located at the submandibular or sub-lingual site. At the ultrasound exam these cysts are usually echogenic and it is often unclear whether they are solid or cystic. At the CT, the central cavity appears filled with a homogeneous, hypo-attenuating fluid material. Furthermore, the cyst can also appear heterogeneous due to the various germ components. It is possible to find fluid-fluid levels with supernatant lipids. MRI images show the topographic relationship of these cysts with the mylohyoid muscle in the oral floor and facilitate the choice of the surgical approach.

\section{Haemangiomas and vascular malformations}

Haemangiomas are benign neoplasms of the capillary endothelium that generally appear within a few weeks of birth. They are the most common benign tumours in the paediatric age, being found in 10-12\% of newborns and even higher percentages in premature babies (up to $20 \%$ ). There are two classifications of haemangiomas; the first, of anatomopathological type, subdivides haemangiomas into:

- subcutaneous forms: characterised by a mainly tangential development;

- tuberous forms: in which an exophytic growth in relief with respect to the cutaneous plane is observed;

- mixed forms: in which there is both, a hypodermic component, and a superficial tuberous component, tuberous forms, mixed forms.

The second classification, of a clinical type, classifies haemangiomas into:
- superficial or capillaries: that clinically present a characteristic 'strawberry' appearance;

- deep haemangiomas: which appear as tumours covered with normal skin - therefore the diagnosis is entrusted to the US;

- mixed haemangiomas: when superficial haemangioma occurs associated with a deep one.

The diagnosis of haemangiomas is usually clinical, based on the semiological characteristics and especially on the natural history of the lesion. The Doppler and the Eco-Doppler are, however, useful exams in cases where angiomatous swelling needs to be differentiated from a venous malformation or from a lymphangioma. On a scan, it is displayed as an expansive and highly vascularised formation [18] (Fig. 13).

The data obtained from the Eco-Colour Doppler survey are fundamental both for the identification of further in-depth diagnostic investigations, including invasive ones, and for the anticipation of the subsequent therapeutic programme.

In the case of haemangiomas, the Eco-Colour Doppler provides useful information on the localisation of the afferent vessels (generally radial conformation) and in the definition of the mass depth.

MRI is recommended in the most problematic haemangiomas, such as laryngeal ones that can interfere with the respiratory function or hepatic ones that, due to their volume and the consequent shunt, can cause a cardiac overload. A vascular malformation can have different prevalent components: capillary, arteriosus, venous, arteriovenous, lymphatic or mixed. It is found at birth and tends to grow proportional to the patient's development [19].

Eco-Colour Doppler is the first exam in the study of these malformations. It allows the evaluation of the thickness of the dermis and subcutaneous tissue, the density of the malformed capillaries and their extension in depth. It also allows the clinician to highlight the presence of malformed subcutaneous veins, studying their morphology, course, confluence and flow characteristics, or to identify arterio-venous micro-shunts, investigating their distribution and flow rate. 


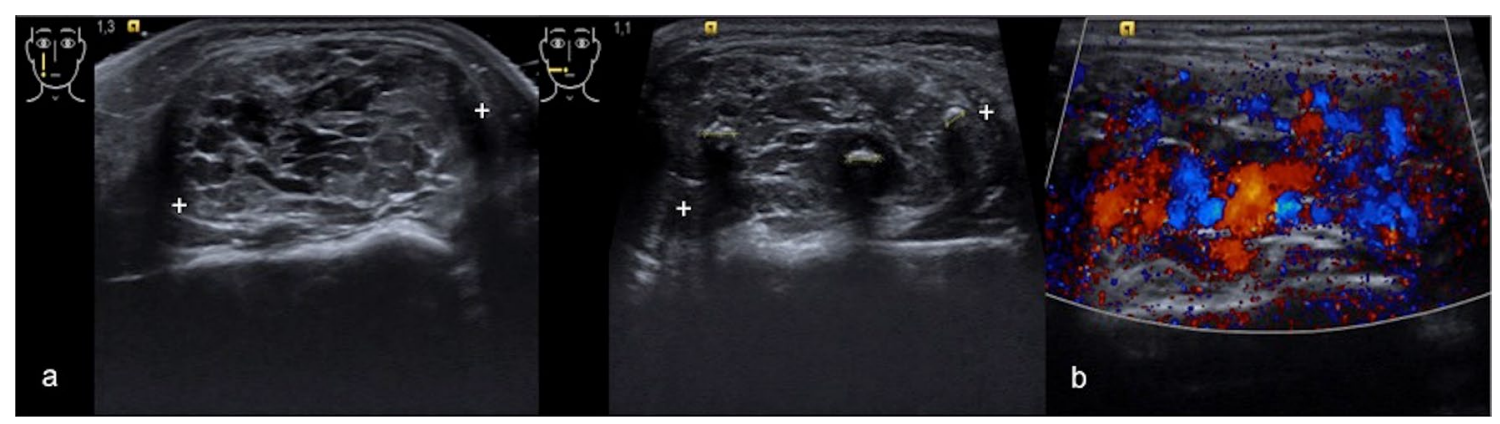

Fig. 13 Cervical masses-haemangioma. a Grayscale axial and longitudinal views of cheek show subcutaneous nonspecific echogenic, welldemarked mass; b colour Doppler module shows hypervascularisation—consistent with a haemangioma

It is sometimes difficult to study on a scan, as probes can induce its compression - this being especially true when prevalent venous components are found. Vascular malformation with prevalent lymphatic components (lymphangioma) is instead hardly compressible, displaying a multicystic appearance (hygroma colli) [20] (Fig. 14).

\section{Cervical thymus}

During its embryonic phase, the thymus generates from the neck, running all the way down to its final retrosternal location. Thymic residues - or indeed the whole organ — can be found anywhere along this path or inside the thyroid.

Ectopic thymic residue can have a cystic or solid appearance, with its echostructure varying depending on the patient's age [21, 22] (Figs. 15,16).

\section{Fibromatosis colli}

Fibromatosis colli or sternocleidomastoid tumours are a rare cause of benign neck mass in infants. They are thought to be due to ischaemia or haemorrhage of such muscle and are linked to the use of forceps during delivery.
Ultrasound is the first choice of exam; the sternocleidomastoid muscle is broadly spread and takes on a fusiform shape with consequent shortening. The echogenicity is variable [23] (Fig. 17). At real-time ultrasound, the enlarged area moves synchronously with the sternocleidomastoid, thus confirming the diagnosis. Sometimes diagnostic integration with CT or MRI is needed to further characterise the disease and know the extent of the involvement.

\section{Pilomatrixoma}

Pilomatrixoma is a benign tumour of the subcutaneous tissue. It generally develops in the head and neck area and is usually not associated with other signs or symptoms (isolated). It appears most commonly in people under the age of 20. It contains keratinised cells and often calcifications. On a scan, it appears as a superficial oval formation, heterogeneously hyperechoic with a hypoechoic halo and calcifications [24] (Fig. 18).

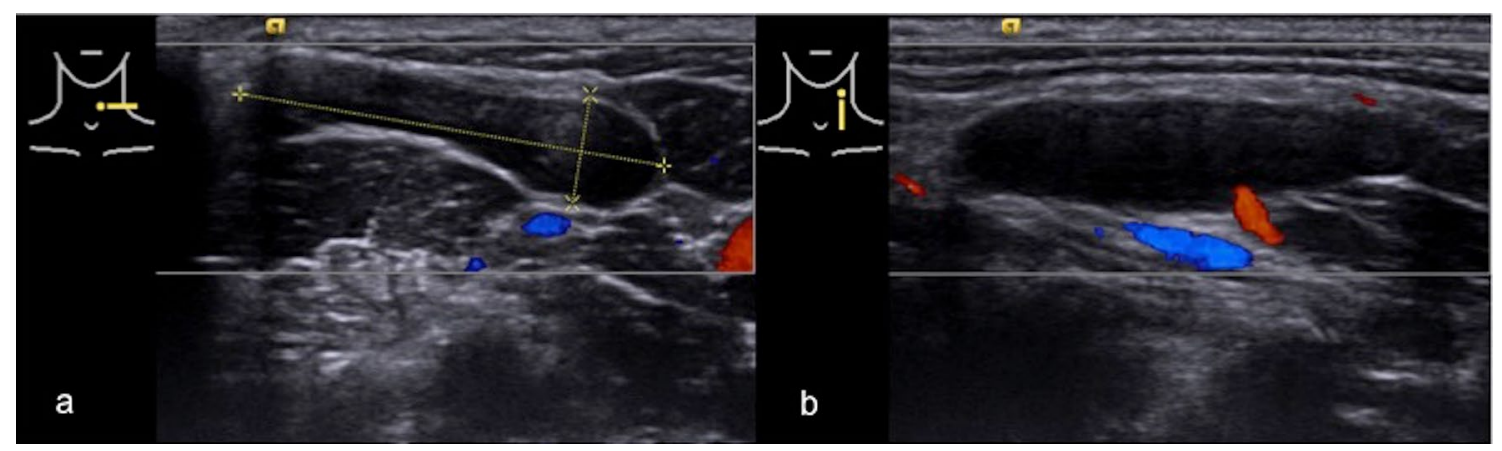

Fig. 14 Hygroma colli. a Axial and b longitudinal views of hypoechoic cystic (++) trans-spatial lesion with thin septa and internal debris 


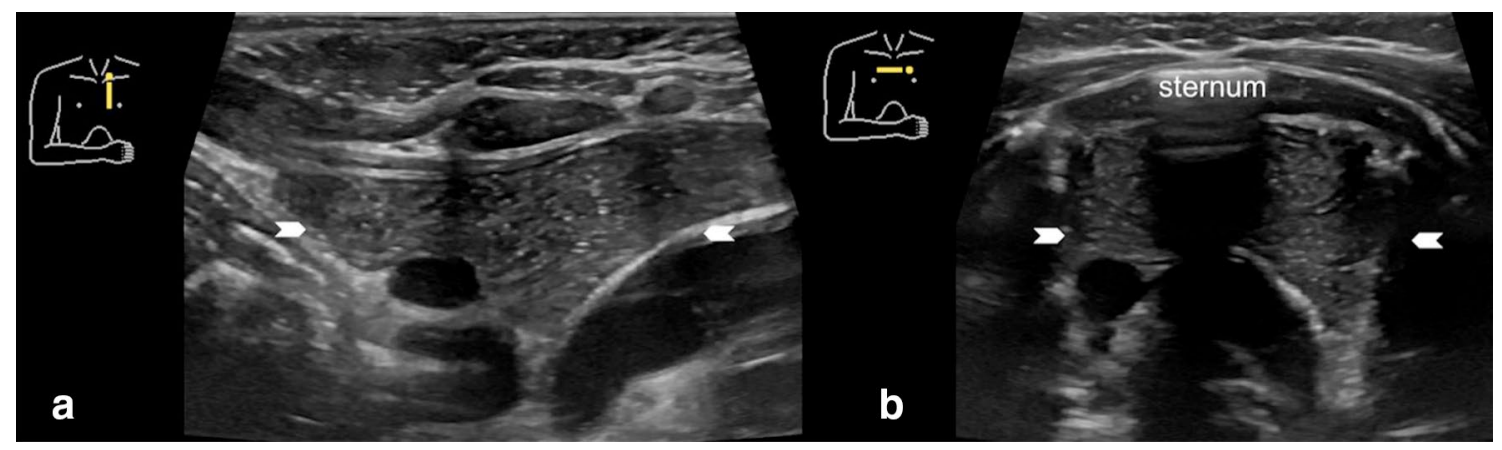

Fig. 15 Thymus. Longitudinal (a) and axial sections (b) of thymus (white arrowheads). The thymus is usually hypoechoic with thin hyperechoic straps, though echogenicity increases with age

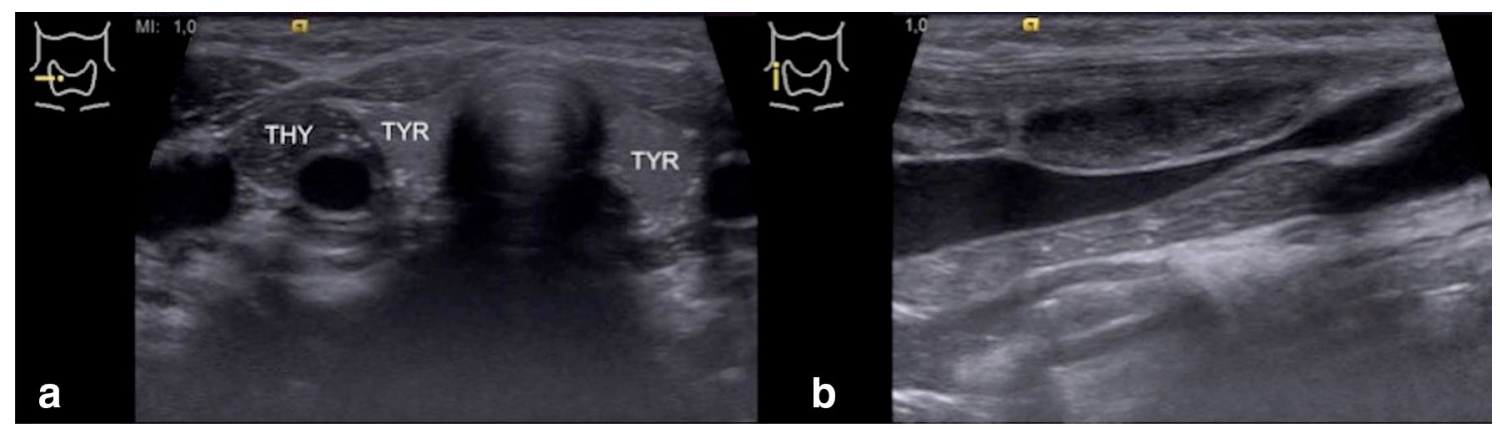

Fig. 16 Cervical thymus. a Axial and b sagittal views of cervical ectopic thymus (THY) adjacent to thyroid gland (TYR). No connection to mediastinum

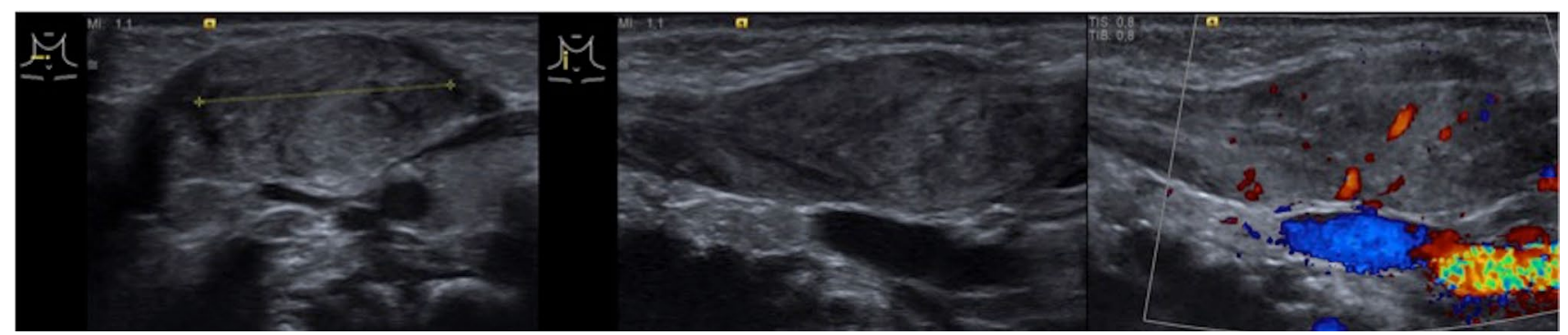

Fig. 17 Neck fibromatosis. a Axial and $\mathbf{b}$ sagittal views of a fusiform thickening mass (++) affecting the sternocleidomastoidal muscle 
Fig. 18 Pilomatrixoma. a Axial and $\mathbf{b}$ sonographic views of subcutaneous partially calcified inhomogeneous mass $(++)$ of the neck. $\mathbf{c}$ The X-ray view shows a calcified mass of the neck (arrow)

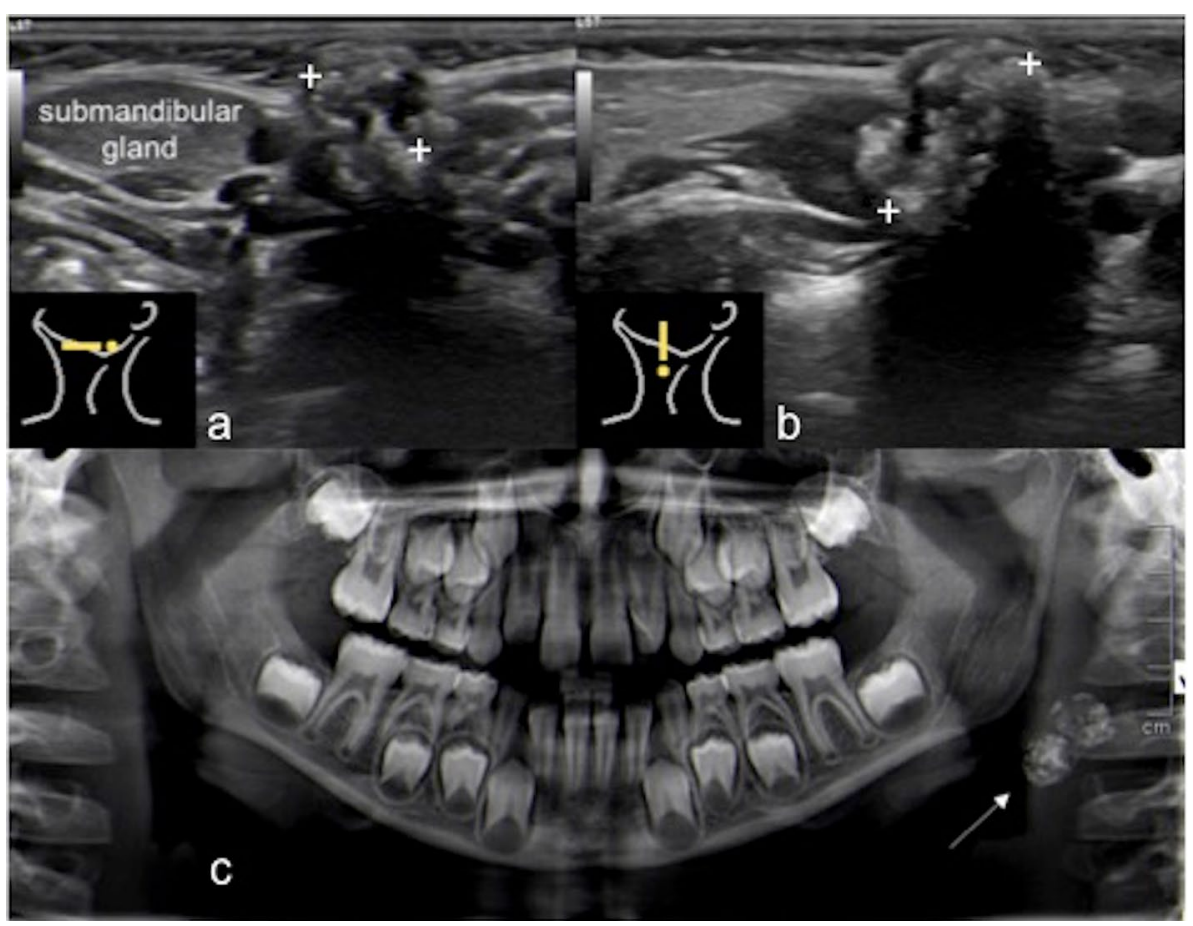

\section{Compliance with ethical standards}

Conflict of interest The authors declare that they have no conflict of interest.

Ethical approval All procedures followed were in accordance with the ethical standards of the responsible committee on human experimentation (institutional and national) and with the Helsinki Declaration of 1975, and its later amendments.

Human and animal rights This article does not contain any studies with human or animal subjects performed by any of the authors.

Informed consent Additional informed consent was obtained from all the patients for which identifying information is not included in this article.

\section{References}

1. Meuwly JY, Lepori D, Theumann N et al (2005) Multimodality imaging evaluation of the pediatric neck: techniques and spectrum of findings. Radiographics 25:931-948

2. Ghervan C (2011) Thyroid and parathyroid ultrasound. Med Ultrason 13:80-84

3. Gharib H, Papini E, Paschke R, Duick DS, Valcavi R et al (2010) AACE/AME/ETA guidelines American association of clinical endocrinologists, associazione medici endocrinologi, and european thyroid association medical guidelines for clinical practice for the diagnosis and management of thyroid nodules. Endocr Pract 16:63-102

4. Bialek EJ, Jakubowski W, Zajkowski P, Szopinski KT, Osmolski A (2006) US of the major salivary glands: anatomy and spatial relationships, pathologic conditions, and pitfalls. Radiographics 26(3):745-763
5. García CJ, Flores PA, Arce JD, Chuaqui B, Schwartz DS (1998) Ultrasonography in the study of salivary gland lesions in children. Pediatr Radiol 28:418-425

6. Chang YW, Hong HS, Choi DL (2009) Sonography of the pediatric thyroid: a pictorial essay. J Clin Ultrasound 37:149-157

7. Hong HS, Lee EH, Jeong SH, Park J, Lee H (2015) Ultrasonography of various thyroid diseases in children and adolescents: a pictorial essay. Kor J Radiol 16(2):419-429

8. Avula S, Daneman A, Navarro OM (2010) Incidental thyroid abnormalities identified on neck US for non-thyroid disorders. Pediatr Radiol. https://doi.org/10.1007/s00247-010-1684-9

9. Ying M, Ahuja A, Brook F (2002) Sonographic appearances of cervical lymph nodes: variations by age and sex. J Clin Ultrasound 30:1-11

10. Ying M, Ahuja A, Brook F, Metreweli C (2000) Power Doppler sonography of normal cervical lymph nodes. J Ultrasound Med 19:511-517

11. Restrepo R, Oneto J, Lopez K, Kukreja K (2009) Head and neck lymph nodes in children: the spectrum from normal to abnormal. Pediatr Radiol 39:836-846

12. Lindeboom JA, Smets AM, Kuijper EJ, van Rijn RR, Prins JM (2006) The sonographic characteristics of nontuberculous mycobacterial cervicofacial lymphadenitis in children. Pediatr Radiol 36:1063-1067

13. Michelini ME, Casadio G, Franchella A (2003) Thyroglossal duct cysts. A retrospective study. Minerva Pediatr 55(1):51-54

14. Turkyilmaz Z, Sonmez K, Karabulut R, Demirgoullari B, Sezer C et al (2004) Management of thyroglossal duct cysts in children. Pediatr Int 46(1):77-80

15. Brousseau VJ, Solares CA, Xu M, Krakovitz P, Koltai PJ (2003) Thyroglossal duct cysts: presentation and management in children versus adults. Int J Pediatr Otorhinolaryngol 67(12):1285-1290

16. Wong KT, Lee YY, King AD, Ahuja AT (2008) Imaging of cystic or cyst-like neck masses. Clin Radiol 63:613-622

17. Nocollas R, Guelfucci B, Roman S, Triglia JM (2000) Congenital cysts and fistulas of the neck. Int J Pediatr Otorhinolaryngol 55(2):117-124 
18. Donnelly LF, Adams DM, Bisset GS (2000) Vascular malformations and hemangiomas: a practical approach in a multidisciplinary clinic. Am J Roentgenol 174:597-608

19. Mulliken JB, Glowacki J (1982) Hemangiomas and vascular malformations in infants and children: a classification based on endothelial characteristics. Plast Reconstr Surg 69:412-422

20. Di Serafino M, Mercogliano C, Severino R et al (2016) Cystic hygroma of the neck: ultrasound findings. Open J Radiol 6:121-124

21. Di Serafino M, Esposito F, Severino R et al (2016) Think thymus, think well: the chest X-ray thymic signs. J PedMoth Care 1(2):108
22. Wang J, Fu H, Yang H, Wang L, He Y (2011) Clinical management of cervical ectopic thymus in children. J Pediatr Surg 46:e33-e36

23. Bedi DG, John SD, Swischuk LE (1998) Fibromatosis colli of infancy: variability of sonographic appearance. J Clin Ultrasound 26:345-348

24. Agarwal RP, Handler SD, Matthews MR, Carpentieri D (2001) Pilomatrixoma of the head and neck in children. Otolaryngol Head Neck Surg 125:510-515 